\title{
The Study of Pallet Pooling Information Platform Based on Cloud Computing
}

\author{
Jia-bin Li $\mathbb{D}^{1,}{ }^{1,2}$ Shi-wei He $\mathbb{D D}^{1}{ }^{1}$ and Wei-chuan Yin $\mathbb{D}^{1}$ \\ ${ }^{1}$ School of Traffic and Transportation, Beijing Jiaotong University, Beijing 100044, China \\ ${ }^{2}$ School of Business Administration, Henan University of Engineering, Zhengzhou 451191, China \\ Correspondence should be addressed to Shi-wei He; shwhe@bjtu.edu.cn
}

Received 15 September 2017; Revised 30 January 2018; Accepted 12 February 2018; Published 20 May 2018

Academic Editor: Emiliano Tramontana

Copyright (c) 2018 Jia-bin Li et al. This is an open access article distributed under the Creative Commons Attribution License, which permits unrestricted use, distribution, and reproduction in any medium, provided the original work is properly cited.

Effective implementation of pallet pooling system needs a strong information platform to support. Through the analysis of existing pallet pooling information platform (PPIP), the paper pointed out that the existing studies of PPIP are mainly based on traditional IT infrastructures and technologies which have software, hardware, resource utilization, and process restrictions. Because of the advantages of cloud computing technology like strong computing power, high flexibility, and low cost which meet the requirements of the PPIP well, this paper gave a PPIP architecture of two parts based on cloud computing: the users client and the cloud services. The cloud services include three layers, which are IaaS, PaaS, and SaaS. The method of how to deploy PPIP based on cloud computing is proposed finally.

\section{Introduction}

The pallet pooling system refers to the management system of renting, recycling, tracking, and maintaining of pallets by professional companies [1]. Zhang Xueyan [2] pointed out that an effective operation of pallet pooling system on the one hand depends on a good mode; on the other hand, it needs a strong information platform to support. Therefore, the construction of the PPIP is particularly important and it has been studied by some researchers [3-15]. For example, Based on RFID technologies Jinshou Song et al. [3]; Liu Ye et al. [4]; Li Xiao et al. [5]; Xu Qi et al. [6]; Liang Q et al. [7]; Murray. J [8]; Ding Z et al. [9]; Bottani E et al. [10]; Harris J S et al. [11]; Lin X Z [12]; Ilic A et al. [13]; Vitzthum S et al. [14]; Elia $\mathrm{V}$ et al. [15] analyzed the architecture, functions and business processes of the pallet pool information system. Based on grid technology, Ren J et al. [16] gave a seven tier architecture and five-tier security framework of a railway pallet pool information system. Based on SOA and RFID, Zhang X et al. [17] analyzed the Chinese pallet pool information system which consisted of a public information system and a set of terminal information systems. Based on cloud computing, Ren J et al. [18] proposed a PPIP which included four layers.
Daniluk D et al. [19] and Niharika G [20] described an approach and architecture based on cloud computing for logistics business, but they did not study the PPIP.

From the above, we know that most of the PPIP were based on the traditional information infrastructures and technologies. The PPIP based on traditional information infrastructures and technologies are vulnerable to the restrictions of hardware, software, information resource utilization, and business processes. Cloud computing is an effective way to build a dynamic information system infrastructure. But there are few studies to PPIP based on cloud computing. Although there is one cloud platform research in PPIP, it did not discuss it in detail. Therefore, this paper further studies the business model and the needs of PPIP based on cloud computing. The paper is structured as follows: The first section gives an introduction and literature review of PPIP. Section 2 presents the meaning of cloud computing architecture and its advantages. Section 3 gives a business model and needs analysis of the PPIP under cloud computing. Section 4 designs an architecture and deployment model of PPIP based on the cloud computing. Section 5 concludes the paper for further research. 


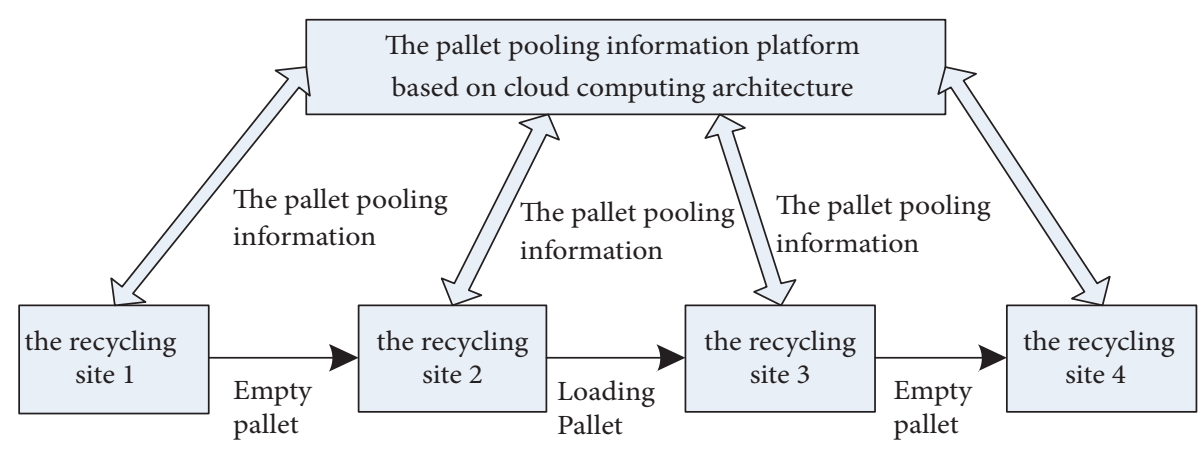

FIGURE 1: The business model of pallet pooling.

\section{The Meaning of Cloud Computing Architecture and Its Advantages}

The meaning of cloud computing can be interpreted from different perspectives. This article uses the official NIST definition [21]: cloud computing is a model for enabling ubiquitous, convenient, on-demand network access to a shared pool of configurable computing resources (e.g., networks, servers, storage, applications, and services) that can be rapidly provisioned and released with minimal management effort or service provider interaction. Cloud computing has the advantages of strong computing power, virtualization, high reliability, high versatility, high flexibility, on-demand services, low cost, and other advantages.

We can understand the meaning and its advantages of cloud computing architecture like this: cloud computing architecture looks like a power plant with centralized power supply architecture; the users do not need to buy their own power generation equipment; they use electricity based on their needs only by a wire which gets access to the grid. The same is to the cloud computing architecture; the users do not need to buy new information system hardware and related software; just with a network cable they can get access to the cloud services provided by service providers. This kind of architecture will greatly reduce the cost and time to build a variety of information systems.

\section{The Business Model and Needs Analysis of PPIP under Cloud Computing}

3.1. The Business Model of Pallet Pooling System under Cloud Computing Architecture. The business model of the pallet pooling system under cloud computing architecture is shown in Figure 1.

The system consists of a pallet pooling information platform based on cloud computing architecture and an extensible pallet recycling network. The PPIP is mainly composed of servers, communications, and other components which are built on the cloud for storage, transmission, and handling of pallet pooling information. Pallet recycling network includes all the enterprises like pallet suppliers, pallet renting, and recycling customers and other logistics enterprises belong to the recycling network. The PPIP supports mobile phones, tablet PCs, laptops, car terminals, and other equipment as the system entrance.

Pallet renting and recycling customers complete the specific business through the portal entrance to the cloud, including the demand for pallet renting, pallet tracking, pallet recycling, and so on. The main work of the PPIP is to coordinate the management of the renting and recycling sites. Through the PPIP, it can set the relevant parameters of the whole pallet pooling system, such as the rental rate and deposit and so on. At the same time, the renting and recycling information on the leased outlets is used to calculate the distribution and flow of all the shared pallets which may improve the decision of inventory configuration and empty pallet dispatching.

3.2. Needs Analysis of PPIP under Cloud Computing Architecture. The PPIP is the core of the entire pallet pooling system. In order to promote the seamless integration of business flow, logistics, and capital flow among the information platform enterprises, pallet customers, and the pallet suppliers, the PPIP should use the information technologies such as RFID (Radio Frequency Identification), GPS (Global Positioning System), GIS (Geographic Information System), and EDI (Electronic Data Interchange) to collect, store, transmit, and process the information timely according to the requirements of the pallet pooling business model and process.

Other than providing pallet pooling suppliers and customers with on-line transaction support such as pallet recycling, pallet transportation and tracing, the charge counting and other business, the platform also provides big data analysis and other value-added services for all the users of the PPIP. Through the analysis of the business model and technical requirements of the PPIP, we could easily get the "cloud computing" characteristics of the PPIP as follows:

(a) The Demand for Hardware and Software Resources in the PPIP Is Flexible and Massive. With the increasing size of the pallet pooling system, there will be new enterprises to join in. Thus the PPIP needs to collect, store, process, and integrate massive information from production enterprises, logistics 


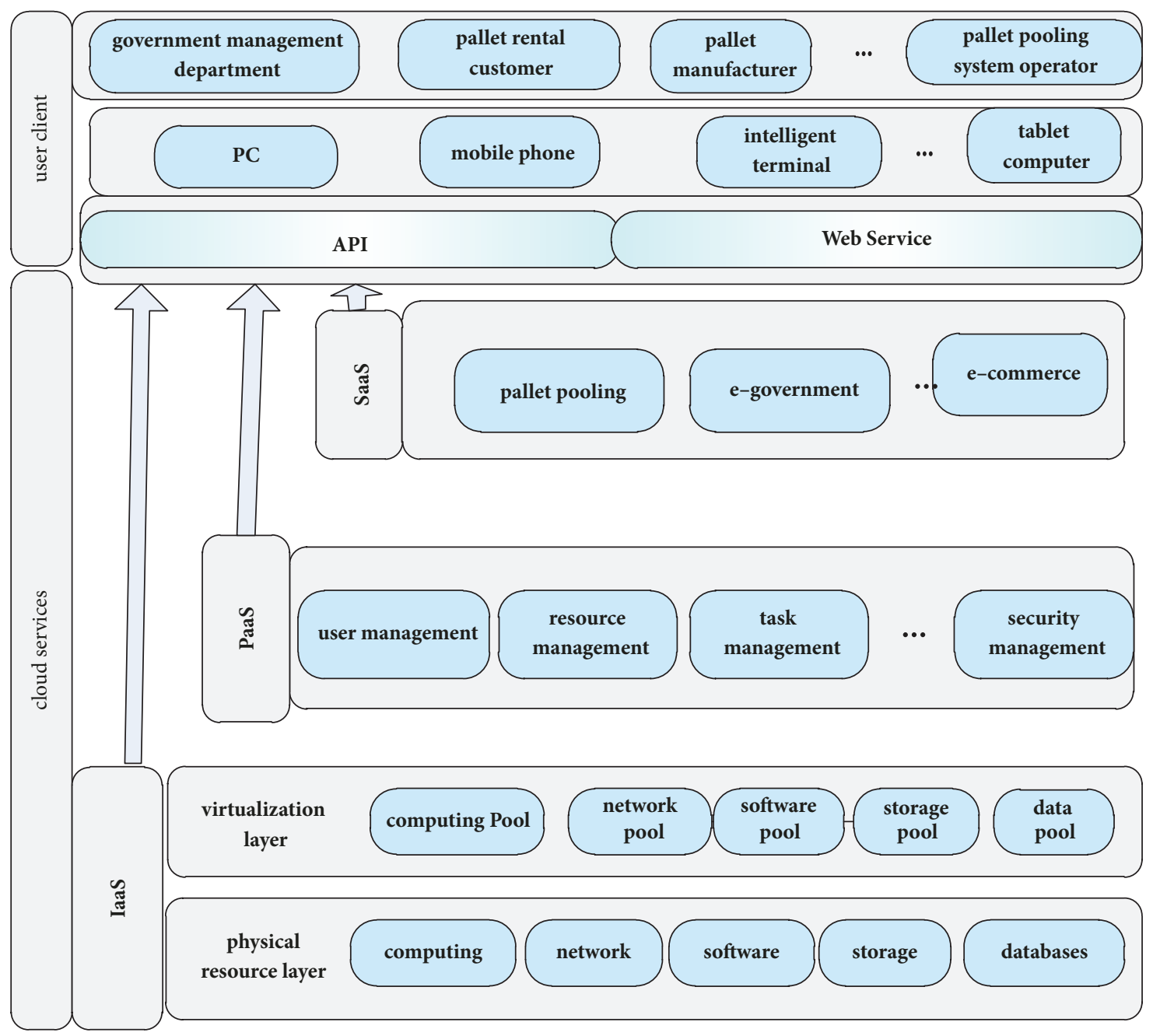

FIGURE 2: The PPIP architecture diagram under cloud computing.

enterprises, government departments, and other links which requires flexible and massive information system in real time.

(b) The Big Load Changes of the PPIP. The PPIP provides the pallet pooling suppliers and customers, logistics enterprises, and government departments with many logistics services. The demand for logistics services is subject to rises and falls with the level of production and consumption of goods which results in a large number or little of hardware and software resources requirements for the PPIP.

(c) The PPIP Based on Cloud Computing Is Easily Accepted by the Users. At present, most of small logistics enterprises, manufacturing enterprises, and retail enterprises have no mature logistics information systems because they could not spend a lot of money on purchasing and developing large and complex logistics management information systems; the PPIP under cloud computing architecture well met their information management requirements of business, which has the advantages of volume charging, low cost, rich interfaces, and easy sharing.

\section{The Architecture and Deployment Model of PPIP Based on Cloud Computing}

4.1. The Architecture of PPIP Based on Cloud Computing. Architecture refers to the logical structure which is used to represent and formalize the relationship between the various components. In this paper, it introduces a cloud computing architecture for constructing the information platform of the pallet pooling system borrowing from the literature. The information platform architecture based on cloud computing adopts hierarchical design which includes the following aspects: cloud infrastructure layer (IaaS), cloud platform layer (PaaS), cloud application layer (SaaS), and user client. See Figure 2 in detail.

(a) Cloud Infrastructure Layer (IaaS). This layer includes the physical resource layer and the resource pool layer (or virtualization layer) under the cloud computing architecture, which is primarily intended to provide hardware infrastructure as a service to the users. Physical resources include computing resources, network resources, storage resources, databases, 
and software resources. The resource pool layer includes computing resource pool, storage resource pool, network resource pool, data resource pool, and software resource pool. Companies that offer an IaaS include Amazon, Microsoft, VMware, Rackspace, and Red Hat.

After the introduction of IaaS layer for the PPIP, all the related parties do not need to build their own hardware facilities. They all share a virtual equipment pool composed of multiple facilities and equipment allocated dynamically according to the actual needs. Then it can attain the goal of quickly building and decreasing fixed capital investment and equipment operating costs.

(b) Cloud Platform Layer (PaaS). The PaaS layer includes user management, resource management, task management, security management, and other modules. This layer provides information system development environment services to the users so they can develop and share their required applications with relevant users.

By using any PaaS service from Google App Engine, Microsoft Azure, Force.com, Heroku, Engine Yard, and so on, the users of PPIP can develop and deploy its pallet pooling information systems that realize the collection, storage, calculation, statistics analysis, sharing, and other functions. This layer also meets the big data and real time processing requirements of the pallet pooling system by use of distributed storing and computing technologies.

(c) Cloud Application Layer (SaaS). This layer is to provide services including pallet pooling, e-government, e-commerce, and other services through the Internet. The pallet pooling services include business applications such as the release of pallet renting and recycling demand information, pallet cargo tracking, pallet inventory management, and pallet pooling cost settlement. E-government includes the portal platform, document exchange, command coordination, single sign on, and certification authority interfaces and so on that distinguish it from the past ones that must be communicated through the traditional way. E-commerce mainly includes the on-line business marketing, on-line pallet rental, and other applications on the network.

In this mode, the service providers of PPIP deploy the pallet pooling application software on its own cloud servers. The users of PPIP do not need to purchase, build, and maintain the infrastructure or application software; they just pay for the actual use of appropriate application software according to the number and the length of time. The PPIP service providers are responsible for the full management, maintenance, and upgrading of the software, allowing users to use the platform at any time and anywhere with its latest version.

(d) The Pallet Pooling Client. The users of the PPIP under cloud computing architecture mainly include government management departments, pallet suppliers and customers, and pallet pooling system operators. All users can get access to the PPIP through the web service or API (APP by mobile) by using hardware like mobile phone, notebook computer, intelligent terminal, tablet computer, and so on.
It must be stated that the construction of the PPIP under cloud computing architecture may be established on a hierarchical basis based on different levels, or by integrating these parts into a whole, each of which performs its own different functions. This information system provides a fast, secure, inexpensive, and secure information service for the pallet pooling system.

4.2. The Deployment Model of PPIP Based on the Cloud Computing. There are four kinds of cloud computing for deployment, including public cloud, private cloud, hybrid cloud, and industry cloud. These four modes can be fit for different application requirements with different advantages and disadvantages. According to the business characteristics and requirements of the PPIP, it is obvious that the PPIP under the cloud computing architecture should adopt the hybrid cloud deployment mode, that is, the combination of private cloud and public cloud. The non-main applications use the public cloud, while for the key, confidentiality and core applications use the private cloud. This will balance the security and the cost between private cloud and public cloud.

\section{Conclusion}

This paper presents a PPIP based on the cloud computing architecture. Of course, this paper only put forward an application model and the basic framework of PPIP with cloud computing; there must be a gap for the real implementation. How to combine the practicality of the pallet pooling system with fully implementing the information platform under the framework of cloud computing remains to be further studied in detail.

\section{Conflicts of Interest}

The authors declare that there are no conflicts of interest regarding the publication of this paper.

\section{Acknowledgments}

The authors would like to thank Dr. Ming-kai BI who has helped them a lot to improve the English sentences and style of the paper.

\section{References}

[1] L. Tai-Ping, "Study on the pattern of overseas pallet circulation and its implication," Logistics Sci-Tech, vol. 6, pp. 73-77, 2008.

[2] X. Y. Zhang and J. W. Ren, "The conception model of pallet pool system," China Market, vol. 11, pp. 23-26, 2009.

[3] S. S. Jin, Q. X. Xiong, M. X. Jiang et al., "Study on chinese pallet pool Co.Ltd and its construction stratagem," Industrial Engineering Journal, vol. 11, no. 4, pp. 19-23, 2008.

[4] Y. Liu, "Study on the Solution Program for pallet pooling information platform," Value Engineering, vol. 31, no. 30, pp. 184-185, 2012.

[5] L. Xiao, S. Jin, and D. Z. Feng, "A pallet rental system based on RFID," Journal of Zhejiang University of Technology, vol. 6, pp. 666-669, 2011. 
[6] X. U. Qi, "Collaborated optimal pricing strategy of pallets pooling supply chain system," China Business \& Market, vol. 7, pp. 54-59, 2011.

[7] Q. Liang, Y. Liu, and Y. Wang, "Study on pallet pooling management system based on RFID and big data," Logistics Technology, vol. 8, pp. 406-408, 2014.

[8] J. Murray, "Pallet pool is key to swedish cargo handling efficiency," The Journal of ICHCA, vol. 3, pp. 27-29, 1969.

[9] Z. Ding and Q. Xu, "Research on the RFID-based pallet pool information system," International Conference of Logistics Engineering and Management, pp. 2551-2558, 2010.

[10] E. Bottani and A. Rizzi, "Economical assessment of the impact of RFID technology and EPC system on the fast-moving consumer goods supply chain," International Journal of Production Economics, vol. 112, no. 2, pp. 548-569, 2008.

[11] J. S. Harris and J. S. Worrell, "Pallet management system: a study of the Implementation of UID/RFID technology for tracking shipping materials within the department of defense distribution network," Defense Technical Information Center, 2008.

[12] X. Z. Lin, "Unified traceability information system of logistics pallet based on the Internet of Things," Advanced Materials Research, vol. 765-767, pp. 1181-1185, 2013.

[13] A. Ilic, J. W. P. Ng, P. Bowman, and T. Staake, "The value of RFID for RTI management," Electronic Markets, vol. 19, no. 2-3, pp. 125-135, 2009.

[14] S. Vitzthum and B. Konsynski, "CHEP, the net of things," Communications of the Association for Information Systems, vol. 22, 2008.

[15] V. Duraccio, V. Elia, and A. Forcina, "An activity based costing model for evaluating effectiveness of RFID technology in pallet reverse logistics system," in Proceedings of the International Conference of Numerical Analysis \& Applied Mathematics (Icnaam '15), AIP Publishing LLC, 2015.

[16] J. Ren, X. Zhang, J. Zhang, and P. Wang, "Design of a railway pallet pool information system on grid," International Conference of Logistics Engineering and Management, pp. 1252-1258, 2010.

[17] X. Zhang, J. Ren, and Y. Sui, "Operation model and information system of China pallet pool system," International Conference of Logistics Engineering and Management, pp. 2162-2168, 2010.

[18] J. Ren, "Design of a loose pallet pool based on cloud computing," International Conference of Logistics Engineering and Management, pp. 1111-1115, 2014.

[19] D. Daniluk and B. Holtkamp, "Logistics mall—a cloud platform for logistics," Cloud Computing for Logistics, pp. 13-27, 2015.

[20] G. Niharika and V. Ritu, "Cloud architecture for the logistics business," Procedia Computer Science, vol. 50, pp. 414-420, 2015.

[21] P. Mell, The NIST Definition of Cloud Computing, National Institute of Standards and Technology, 2011. 


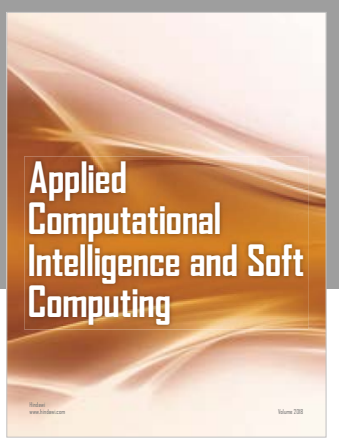

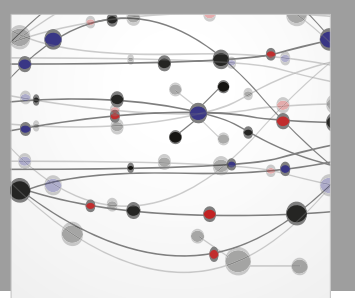

The Scientific World Journal
Submit your manuscripts at

Computing
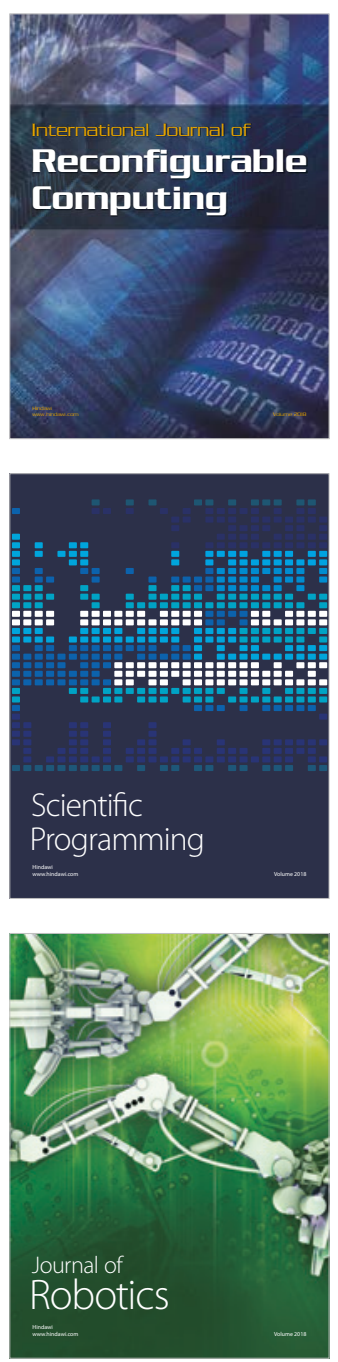

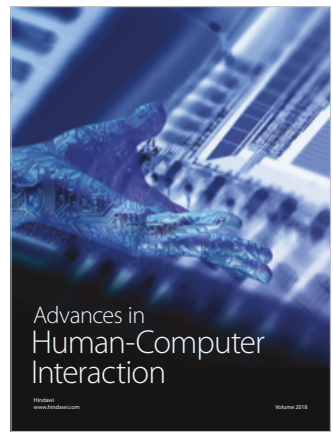

Human-Compute

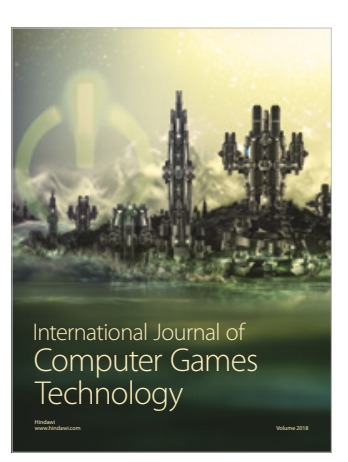

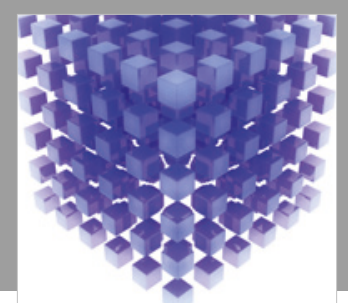

Mathematical Problems in Engineering

\section{Engincering}
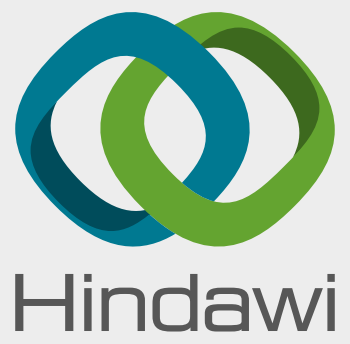

www.hindawi.com
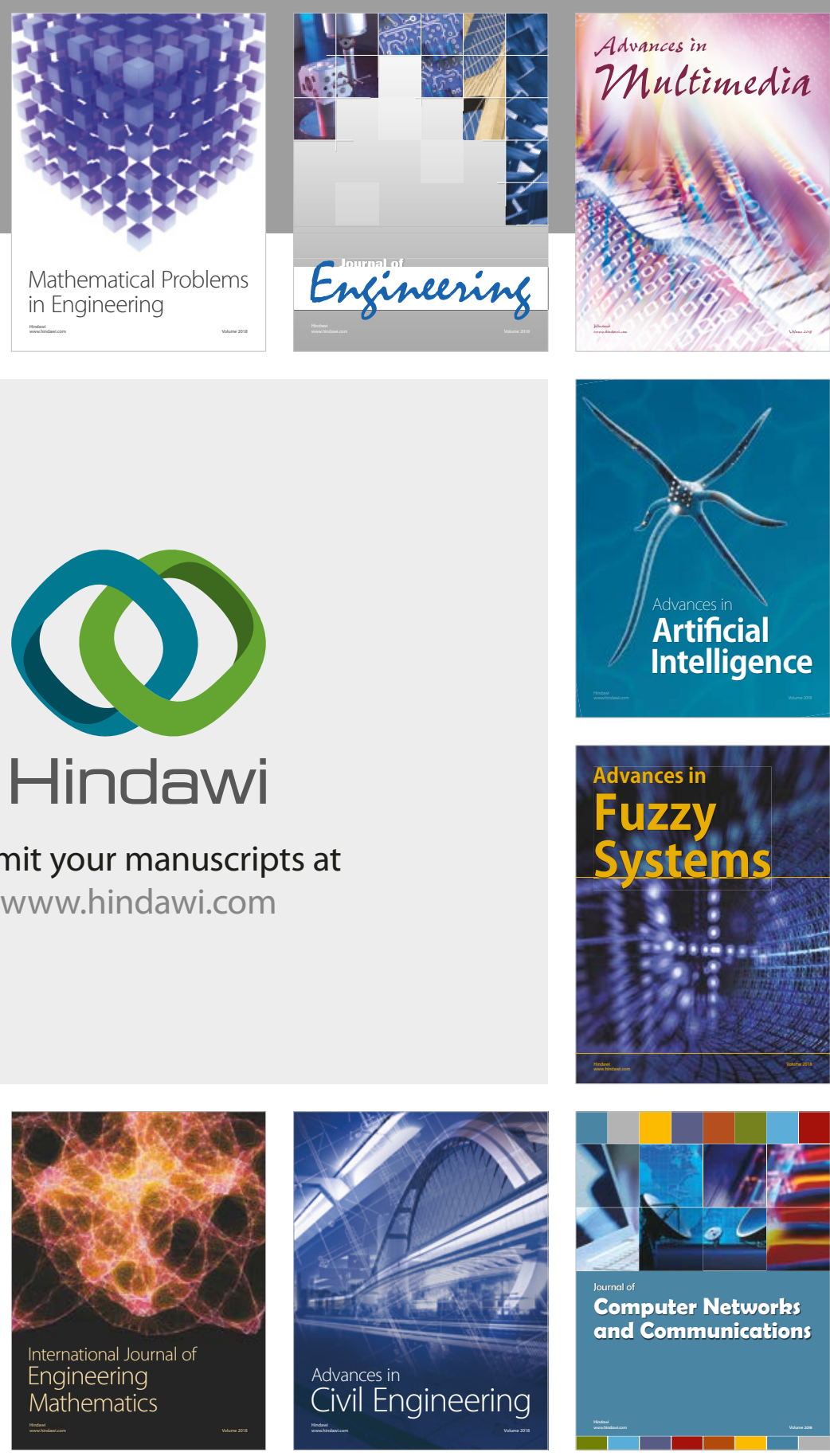

Computer Networks and Communications

Multimedia
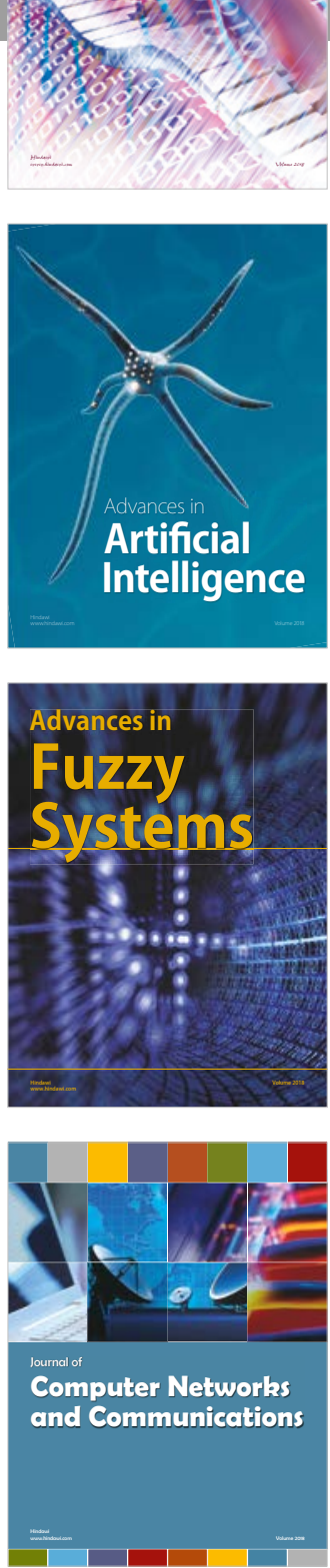

Advances in

Modelling \&

Simulation

in Engineering

interaction

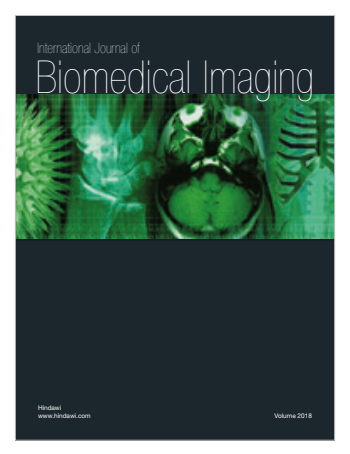

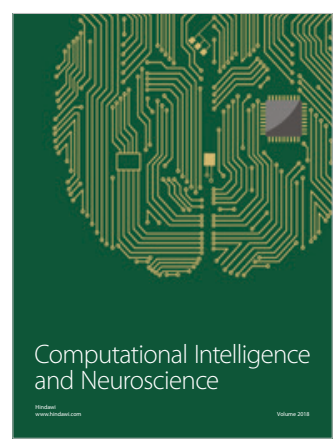

